$\begin{array}{lccr}\text { ALCANÇANDO } & \text { UM } & \text { PÚBLICO } & \text { ESTRANGEIRO: } \\ \text { TRANSFERÊNCIAS } & \text { CULTURAIS } & \text { EM } & \text { TRADUÇÃO } \\ \text { AUDIOVISUAL }^{12} & & & \end{array}$

De Nathalie Ramière, Universidade de Queensland, Austrália

Tradução de Morgana Aparecida de Matos

Universidade Federal de Santa Catarina (UFSC), Brasil

morgana_matos@hotmail.com

Tradução de Willian Henrique Cândido Moura

Universidade Federal de Santa Catarina (UFSC), Brasil

willianhenry_@hotmail.com

Tradução de Antonia Elizangela de Morais Gehin

Universidade Federal de Santa Catarina (UFSC), Brasil

antonia.gehin@gmail.com

D0I: https://doi.org/10.26512/caleidoscopio.v3i1.23830

"A tradução constitui uma experiência cognitiva fundamental da alteridade."

(Brisset, 2003, p.101)

RESUMO: Este artigo analisa algumas das questões que envolvem a tradução intercultural de filmes. Centra-se na tradução de referências e questões culturais específicas, particularmente, a validade das noções de estrangeirização e domesticação em Estudos da Tradução, elaboradas por Venuti (1995), como uma abordagem conceitual tradicionalmente usada para discutir as estratégias empregadas no processo de tradução de referências culturais. Com base nos resultados obtidos em um estudo piloto composto de três filmes franceses dublados e legendados para o inglês, este artigo sugere um desafio teórico ao propor uma abordagem mais pragmática para o estudo da transferência cultural em tradução audiovisual (TAV). De modo particular, propõe a analisar se é possível observar qualquer forma de regularidade no emprego de estratégias de tradução de referências culturais, assim como de que maneira isso impacta as relações dialógicas entre o Eu e o Outro e a representação da alteridade.

Palavras-chave: Tradução audiovisual, Transferência cultural, Referências culturais, estrangeirização, domesticação.

Introdução

12 (n. t.) Este artigo foi publicado inicialmente no The Journal of Specialised Translation, n. 6, de 2006, sob o título de Reaching a Foreign Audience: Cultural Transfers in Audiovisual Translation. A tradução aqui apresentada foi realizada com a autorização da autora. 
Um dos maiores desafios para um filme, após sua estreia nacional, é alcançar o público internacional e fazer sucesso no exterior. Nesse processo de internacionalização, diferenças linguísticas constituem um dos maiores obstáculos, fazendo com que a tradução para o cinema (principalmente na forma de legendagem e dublagem) ${ }^{13}$ adquira grande importância econômica e social. Entretanto, linguagem e cultura estão profundamente interligadas e os tradutores, obviamente, não traduzem palavras isoladas ou fora de contexto, mas textos inteiros culturalmente enraizados e determinados por especificidades presumivelmente compartilhadas pela maioria dos membros da cultura de partida, criando "situações desafiadoras" para a tradução. Ao possibilitar o contato entre duas culturas, a tradução para o cinema, em particular, e a tradução audiovisual, de modo geral, suscitam questões transculturais consideráveis. Ignorar tais questões pode resultar em um produto audiovisual cuja tradução não cumpre sua função de comunicar a mensagem ao público-alvo.

A tradução cultural de filmes envolve múltiplas questões como a escolha daqueles que serão distribuídos no exterior, as estratégias de mercado empregadas na distribuição e as técnicas utilizadas para traduzir um material culturalmente específico.

A tradução de especificidades culturais constitui uma das áreas mais desafiadoras no âmbito da transferência intercultural, a ponto de referências culturais serem tradicionalmente consideradas 'intraduzíveis' (Catford, 1965; Cornu, 1983; Arson, 1988), aproximando-se dos limites da tradução. É particularmente interessante a questão do impacto que estratégias de tradução podem causar na forma como uma cultura estrangeira é percebida pelo público-alvo.

Quando comecei a investigar tais questões, eu estava naturalmente interessada nas noções de estrangeirização e domesticação ${ }^{14}$ desenvolvidas por

\footnotetext{
${ }^{13}$ Legendagem e dublagem não são os únicos modos de tradução audiovisual, conforme Gambier e outros teóricos da área enfatizam (Gambier, 1996; Delabastita, 1989). Contudo, esses modos de tradução audiovisual foram escolhidos como foco do meu projeto de pesquisa principalmente por razões práticas, uma vez que legendagem e dublagem são, de fato, as duas principais formas de tradução para o cinema (Baker e Hochel, 1998: 74).

14 É necessário enfatizar aqui que a origem desses conceitos, apesar de geralmente atribuídos a Venuti, que os trouxe para os Estudos da Tradução com seu instrutivo livro The Translator's Invisibility (1995b) pode, de fato, ser atribuído ao Romantismo alemão e ao trabalho de Schleiermacher (1813). Venuti foi, certamente, significativamente influenciado pela obra de Berman (1995) La traduction comme épreuve de l'étranger.
} 
Venuti (1998a: 67) 15 e sua teoria de que a 'tradução exerce enorme poder na construção da representação de culturas estrangeiras'. Essas noções me levaram a pressupor que a tradução para o cinema, dado seu incrível impacto social e sua visibilidade como um modo de intercâmbio cultural, pode, de fato, afetar as representações culturais em proporção superior a outros tipos de tradução — tanto na maneira com que uma cultura é percebida no exterior, quanto na forma como as culturas percebem umas às outras e a si próprias.

0 modelo estrangeirização/domesticação tem sido reconhecido como uma ferramenta capaz de conceituar a relação entre a cultura de partida (CP) — vista como o 'Eu' - e a cultura de chegada (CC) - vista como o 'Outro'. Por outro lado, esse modelo tem suscitado um amplo debate no campo dos Estudos da Tradução. De acordo com Venuti (1998b: 240), estrangeirização e domesticação, como estratégias de tradução gerais, acontecem em dois níveis: no nível macro - com a seleção dos textos estrangeiros a serem traduzidos - e no nível micro, por exemplo, com os métodos efetivos usados para traduzi-los. Para Venuti (1992; 1995a; 1995b; 1998b), domesticação é uma tendência natural de tradução e consiste em traduzir de forma fluída, idiomática e transparente tendendo a eliminar o estrangeirismo e conformar o texto de partida com as necessidades e os valores da cultura de chegada. Nas palavras do autor:

[Uma] estratégia fluente desempenha um trabalho de aculturação que domestica o texto estrangeiro, tornando-o compreensível e mesmo familiar para o leitor da língua de chegada, proporcionando a ele ou a ela a experiência narcisista de reconhecer a própria cultura na cultura de outro, reafirmando um imperialismo que amplia o domínio da transparência com outros discursos ideológicos sobre uma cultura diferente. (Venuti, 1992: 5)

Estrangeirização, por outro lado, aproxima o leitor do texto de partida por meio de um efeito de desfamiliarização e consiste em "distanciar-se de valores domésticos fundamentais, preservando diferenças linguísticas e culturais." (Venuti, 1998b: 240). Concordando com Schleiermacher (1813) e com Berman (1985), Venuti defende que o método de estrangeirização é "altamente desejável, como uma

\footnotetext{
15 (n. t.) Mesmo que alguns dos trabalhos aqui citados possuam suas traduções oficiais para a língua portuguesa, todas as citações presentes neste artigo foram traduzidas, do artigo original, pelos tradutores.
} 
forma de restringir a violência etnocêntrica da tradução" (1995b: 20) e "tornar o texto traduzido um local onde o outro cultural não é apagado, mas manifestado" (1998b: 242).

Termos diferentes têm sido usados por Venuti e seus seguidores no lugar de 'domesticação', como "naturalização" ou "assimilação". Ao passo que os termos 'exotismo' ou 'exotização' são usados como sinônimos de 'estrangeirização'. De fato, como Kwiecinski (2001: 13) aponta, tais termos "tendem a ser usados de forma ampla e para se referir a diferentes fenômenos, causando lacunas e inconsistências terminológicas". Mais especificamente, Kwiecinski (2001: 15) distingue estrangeirização/domesticação e exotismo/assimilação, e enfatiza que estrangeiro e exótico frequentemente se fundem. Curiosamente, Zlateva (2004: 2) nota que, na realidade, domesticação e estrangeirização "se referem a duas entidades distintas" e não podem ser comparadas tão simetricamente como são: "O que é domesticada é a forma e o conteúdo do texto de partida, e o que é estrangeirizado e exotizado é a forma e o conteúdo do texto traduzido" (ibid.). ${ }^{16}$

Embora, originalmente concebido por Venuti como um ato político cujo intuito é chamar a atenção para a invisibilidade do tradutor, o modelo estrangeirização/domesticação tem sido reapropriado por vários pesquisadores da área de transferência intercultural. Como será demonstrado neste artigo, as estratégias usadas, particularmente na tradução de material culturalmente específico, são frequentemente classificadas de acordo com esse modelo. ${ }^{17}$

Não pretendo questionar aqui a qualidade dos argumentos de Venuti, como, por exemplo, seu posicionamento favorável à estrangeirização de projetos de tradução, mas as noções de estrangeirização e domesticação como concepções teóricas tradicionalmente usadas para discutir a transferência cultural em tradução. Neste artigo, proponho descrever os resultados de um estudo piloto composto de três filmes franceses dublados e legendados para o inglês, elaborado para medir a eficácia do modelo estrangeirização/domesticação em situações empíricas. De

\footnotetext{
16 Embora importante, essas considerações terminológicas não impactam a validade de meu argumento. Por exemplo, o fato de estrangeirização e domesticação serem apresentadas como sistemáticas e mutuamente excludentes.

17 Entretanto, é necessário enfatizar que Venuti usa estrangeirização e domesticação em amplo sentido, uma vez que esses termos se referem, em suas publicações, não somente a estratégias gerais de tradução de itens culturalmente específicos - a maneira como as compreendo aqui - mas também aos conceitos de opacidade/fluência em termos de convenções linguísticas no que concerne ao estilo, sintaxe ou léxico, etc.
} 
modo especial, analisarei se é possível observar qualquer forma de regularidade no uso de estratégias empregadas na tradução de referências culturais e o que isso acarreta para a relação dialógica entre o "Eu" e o “Outro", assim como para a representação da alteridade. Minha intenção, portanto, não é questionar a estrutura conceitual de estrangeirização/domesticação ou alguns dos argumentos de Venuti, como Robinson (1998), Pym (1996) e outros têm feito - como, por exemplo, por meio da argumentação de que estratégias de estrangeirização podem, de fato, exercer um efeito potencialmente negativo ${ }^{18}$ - mas, apresentar um desafio teórico, analisando se o modelo é capaz de elucidar as questões culturais que envolvem o meu corpus e, consequentemente, questões culturais no contexto específico da tradução audiovisual (TAV).

Este artigo não se propõe a analisar a aplicabilidade do modelo estrangeirização/domesticação de forma ampla, como a seleção de filmes a serem distribuídos no exterior ou o papel que o marketing e os paratextos desempenham na familiarização do público com conteúdos potencialmente desconhecidos, apesar da importância dessas ferramentas para a compreensão de como um filme atinge um público estrangeiro e impacta representações culturais. Neste artigo, eu investigo a adequação das noções de estrangeirização e domesticação em tradução, isto é, as estratégias usadas pelos dubladores e legendadores para lidar com referências culturais francesas em inglês. Primeiramente, apresentarei como os procedimentos de tradução de referências culturais são tradicionalmente abordadas na literatura.

18 Esse criticismo se concentra principalmente na relevância da defesa das estratégias de estrangeirização por parte de Venuti. De acordo com Robinson e Baker (ambos citados em Schäffner e Kelly-Holmes, 1995: 32), tentar marcar a alteridade em um texto de chegada pode, de fato, ser tão egocêntrico quanto pode reforçar uma certa imagem do estrangeiro fazendo-o parecer 'exótico' ou 'primitivo'. Outros autores como Snell-Hornby (1996: 34), Lindfors (2001) e Faiq (2004) têm proposto argumentos similares. A defesa de estratégias de estrangeirização tem sido criticada também por favorecer uma certa "elite" capaz de entender a tradução orientada para a cultura de partida (Newmark, 2000). Para um resumo detalhado do criticismo acerca dos argumentos de Venuti, conferir Kwiecinski (2001: 89-95). 


\section{Abordagem tradicional}

\subsection{Definição}

Questões teóricas e práticas levantadas pelas noções de referências culturais são particularmente complexas. Franco Aixelá (1996: 56-57), por exemplo, destaca que:

0 primeiro problema que enfrentamos ao investigar aspectos culturais em tradução é como elaborar uma ferramenta adequada para nossa análise, uma noção de "referência cultural" que nos permita distinguir um elemento cultural de um elemento pragmático ou linguístico. A principal dificuldade para definir um elemento cultural está, obviamente, no fato de que na linguagem tudo é culturalmente produzido, começando pela língua.

Assim, para embasar teoricamente este estudo, a definição de referência cultural elaborada por Olk (2001) no âmbito da tradução textual ${ }^{19}$ foi adaptada aqui para o contexto da tradução fílmica. Eu entendo que material culturalmente específico envolve sinais verbais e não-verbais (visual e auditivo), os quais constituem um problema para a transferência transcultural porque se referem a elementos ou conceitos que são específicos do contexto sociocultural original que o filme representa, isto é, que, no momento da distribuição não existam, ou se afastem significativamente de seu valor conotativo de objetos e conceitos similares, nas culturas-alvo consideradas.

\subsection{Classificação de procedimentos}

Com exceção de Tomaszkiewicz (2001) e Nedergaard-Larsen (1993), que investigaram sistematicamente as estratégias usadas para a tradução de referências culturais para o cinema, a maior parte dos trabalhos de pesquisa nesse campo enfatizam a tradução textual (Ivir, 1987; Florin, 1993; Newmark, 1995; Franco Aixelá, 1996; Mailhac, 1996; Kwiecinski, 2001; Olk, 2001). Embora não seja o foco deste estudo, é interessante analisar em que medida a classificação de

19 "Textual" se refere aqui aos textos escritos ou o oposto de textos audiovisuais ou multissemióticos como filmes ou anúncios publicitários. 
procedimentos de tradução, sugerida por esses autores, pode ser aplicada à tradução audiovisual. Entretanto, meu principal argumento aqui, é que a maioria das classificações de estratégias de tradução seguem uma progressão geral comum, da mais estrangeirizante à mais domesticante, mesmo que essa progressão esteja implícita e, ao mesmo tempo, óbvia em relação à ordem na qual os procedimentos de tradução são apresentados, como no caso de Ivir (1987) e Newmark (1995). Ainda que nem todas as possíveis estratégias de tradução possam ser apresentadas na figura 1, uma vez que não há um consenso quanto ao número, a classificação de procedimentos disponíveis para o tradutor e as tipologias apresentadas pelos diferentes autores, essa progressão característica pode ser observada a seguir:

Figura 1: Típica progressão de procedimentos encontrada na literatura

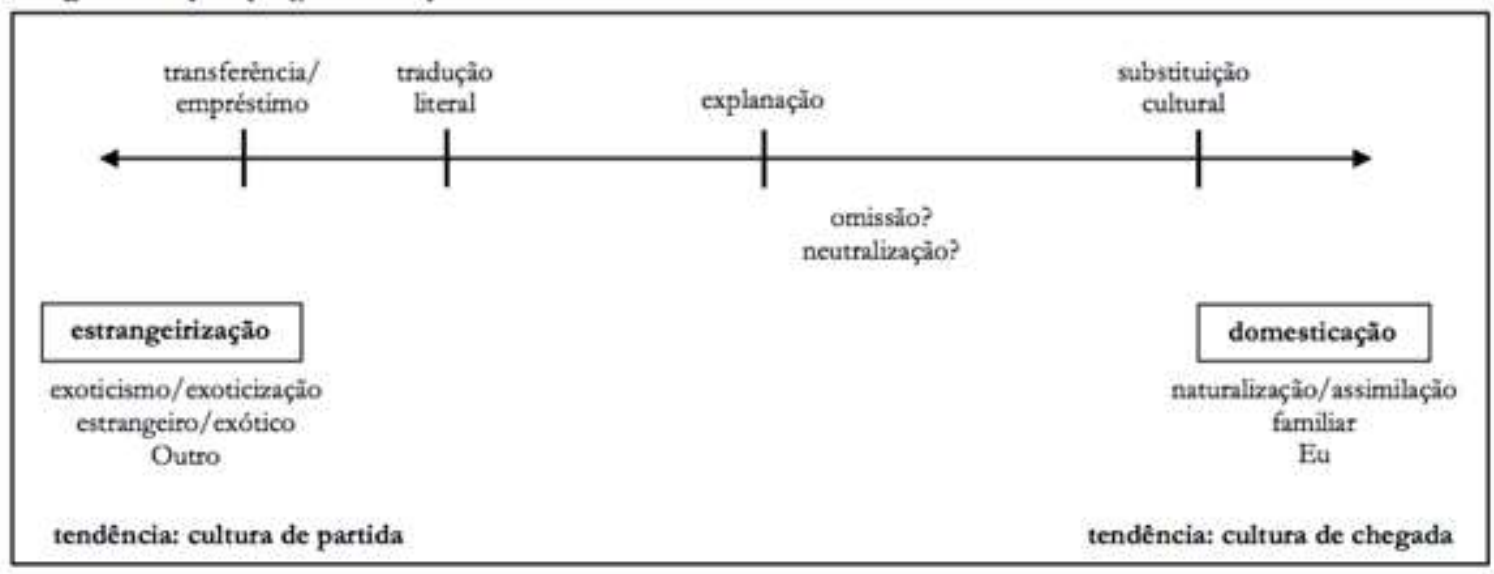

De acordo com esse modelo, os procedimentos de tradução são distribuídos ao longo de uma escala com dois polos normalmente denominados estrangeirização e domesticação, mas também conhecidos como exotismo/assimilação, fonte/alvo, estrangeiro/doméstico, Eu/Outro, etc. Na tabela, cada estratégia de tradução está posicionada no espectro, conforme acomoda o contexto cultural do público-alvo. Esse modelo básico é descrito, por exemplo, por Franco Aixelá (citado em Kwiecinski, 2001: 151), como "uma continuação de vários níveis de manipulação intercultural, definido como uma escala de estratégias de conservação versus substituição".

Meu argumento é que, apesar das variações e similaridades terminológicas quanto à forma que esses termos são entendidos e usados, o modelo traçado para apresentar o conjunto de estratégias de tradução disponíveis é essencialmente o 
mesmo: os dois extremos do espectro representam a tendência com que cada estratégia de tradução (explicitação, tradução literal, substituição cultural, omissão, etc.) é empregada de acordo com seu grau de mediação cultural. 0 modelo é, portanto, claramente baseado em uma polarização na qual cada procedimento de tradução tende na direção de um polo ou de outro, apresentando assim o "Eu" e o "Outro" como mutuamente excludentes.

\subsection{Impacto cultural de estratégias de tradução}

0 argumento apresentado pela maioria dos pesquisadores da área é o de que tradutores têm a sua disposição uma vasta gama de estratégias para traduzir referências culturais e que o tipo de estratégia empregada pode impactar a percepção da cultura de partida por parte do público-alvo. A estratégia empregada pode preservar características da cultura de partida, perpetuar estereótipos positivos ou negativos, bem como enfraquecer ou fortalecer as especificidades culturais, gerando equívocos transculturais e, portanto, influenciando a percepção da cultura de partida pela cultura estrangeira. Venuti (1995a: 23) claramente argumenta, por exemplo, que a tradução é inevitavelmente domesticante, uma vez que é normalmente realizada para atender às necessidades e aos valores da cultura de chegada. Por essa razão, o autor defende o emprego de estratégias estrangeirizantes pelo fato de reterem o estrangeirismo do texto de partida e encorajarem os leitores/telespectadores a se abrirem às diferenças culturais. Similarmente, Olk (2001: 54), tratando especificamente de referências culturais, argumenta que a tradução é uma prática discursiva e que estratégias de tradução podem "influenciar a forma como a cultura de partida é percebida pela cultura de chegada" (ibid.: 56). Tal perspectiva é compartilhada por autores como Jacquemond (1992), Herrero (2000), e Witte (1994).

Além disso, a suposição por trás dessas alegações - uma suposição raramente explicitada por qualquer um dos autores mencionados acima - é a de que o uso de estratégias de tradução é sempre regular, criando, assim, uma norma com um impacto potencial como o mencionado anteriormente. Por exemplo, Franco Aixelá (1996: 60) afirma que: 
obteremos um quadro que nos permitirá descobrir rapidamente a tendência geral de uma tradução em relação à dupla tensão discutida no início deste artigo (sendo uma representação do texto de partida e sendo um texto válido por si só).

Esse argumento serviu de base para o meu projeto de pesquisa e inicialmente me levou a identificar as várias estratégias usadas em legendagem e dublagem para traduzir material culturalmente específico, assim como a sua frequência e o seu impacto nas representações culturais do texto de partida.

Apresentarei, a seguir, os resultados de um estudo preliminar projetado para verificar se essa suposição e, em particular, se o modelo estrangeirização/domesticação e seu impacto na representação de culturas se sustentam empiricamente.

\section{Problemas decorrentes do estudo empírico}

É importante salientar que o meu estudo empírico foi realizado a partir de um pequeno corpus de três filmes legendados e dublados para o inglês: Le dîner de cons (1998), Astérix et Obélix contre César (1999), e Le pacte des loups (2001) ${ }^{20}$. Considerando que cada filme foi traduzido por legendadores e dubladores diferentes, presume-se que o problema formulado abaixo se assemelha ao de um corpus mais extenso.

Ao tentar empregar o típico procedimento de tradução de referências culturais descritas acima, três tipos de problemas empíricos surgiram.

\subsection{Classificação das estratégias}

Inicialmente, foi difícil identificar o procedimento de tradução empregado em alguns casos. Em Le dìner de cons, por exemplo, quando o personagem Pierre Brochant machuca as costas, François Pignon ('le con', que acidentalmente o fez tropeçar] exclama: 'Là, à part un voyage à Lourdes...' [Now, except a trip to Lourdes...][Agora, exceto uma viagem à Lourdes...] ${ }^{21}$, que tem obviamente um efeito

\footnotetext{
${ }^{20}$ (n. t.) Os nomes dos filmes em português brasileiro são: O jantar dos malas (1998), Asterix e Obelix contra César (1999) e $O$ pacto dos lobos (2001).

${ }^{21}$ (n. t.) Os exemplos analisados pela autora foram traduzidos ao português pelos tradutores.
} 
mais irônico, foi traduzido como: - Na legenda: "You'll need a miracle!"22 [Você vai precisar de um milagre!]. Se esta é uma forma de explanação [as pessoas que vão para Lourdes estão, na verdade, buscando um milagre) ou uma neutralização (a referência cultural "à Lourdes" foi omitida), é difícil determinar. 0 fato é que apenas a ideia de que Brochant se encontra em uma situação desesperadora foi preservada. Além disso, é comum o emprego de mais de uma estratégia para solucionar o mesmo problema de tradução, dificultando sua identificação.

Curiosamente, a dificuldade de denominar estratégias, pode, de fato, explicar a multiplicidade de tipologias e classificações encontradas na literatura, uma vez que ao identificar divergências e similaridades naquelas já existentes, a maioria dos pesquisadores parece propor as próprias tipologias, apenas para incorrer nos mesmos problemas ao mapear as próprias classificações. ${ }^{23}$

\subsection{Procedimentos de estrangeirização ou domesticação?}

Apesar desse problema relacionado às tipologias, tentei aplicar as classificações descritas acima ao meu corpus. Depois que as estratégias foram mais ou menos identificadas, o segundo problema constatado ao longo do estudo empírico foi a dificuldade de situá-las no espectro da estrangeirização à domesticação porque não fica claro, por exemplo, se a neutralização e a omissão são formas de domesticação ou estrangeirização. Do ponto de vista cultural, essas estratégias tendem a ser neutras e, portanto, a eliminar a especificidade da cultura de partida. 0 mesmo ocorre com a estratégia explanação, que procura atender às necessidades do público-alvo pela "transformação do estranho em familiar e do específico em comum" (Ivir, 1987: 38), enquanto retém parcialmente a especificidade do texto de partida, já que é frequentemente empregada em combinação com outra estratégia. Em Le pacte des loups, por exemplo, 'le pays du Gévaudan' [o país de Gévaudan] foi dublado como 'the Gévaudan region', [A região de Gévaudan] ${ }^{24}$ indicando o emprego da estratégia de tradução literal em

\footnotetext{
22 Legendas por Alexander Whitelaw. Versão dublada/legendada distribuída por Gaumont, 1998.

23 Para uma revisão crítica detalhada da categorização de procedimentos de tradução, conferir particularmente Olk (2001) a Kwiecinki (2001).

24 Tradutor desconhecido. Versão dublada/legendada distribuída por Universal Studios, 2002.
} 
combinação com a estratégia explanação. Situar a estratégia explanação na escala da estrangeirização à domesticação é, portanto, difícil.

Nota-se que a maioria das estratégias não são assimiladoras ou exotizadoras em si ou de si mesmas, e que suas características potenciais - se relevantes - são determinadas pelo contexto (vide seção 4). Classificações como as descritas na seção 2.2 parecem ser de uso limitado, especialmente no contexto da tradução fílmica.

\subsection{Irregularidade no emprego das estratégias}

Finalmente, apesar dos problemas enfatizados acima (descontextualização e dificuldade de classificar as estratégias), um estudo quantitativo dos procedimentos empregados na tradução dos três filmes, tanto na versão legendada quanto na versão dublada, foi realizado para testar os modelos operacionais baseados nas noções de estrangeirização e domesticação.

Tabela 1 - Conjunto de estratégias de tradução proveniente do estudo

\begin{tabular}{|c|c|c|}
\hline \multicolumn{2}{|c|}{$\begin{array}{c}\text { Le Dîner de Cons } \\
\text { (Francis Veber, 1998) }\end{array}$} \\
\hline $\begin{array}{c}\text { Tipos de } \\
\text { estratégias }\end{array}$ & $\begin{array}{c}\% \text { na } \\
\text { versão } \\
\text { legendada }\end{array}$ & $\begin{array}{c}\% \text { na } \\
\text { versão } \\
\text { dublada }\end{array}$ \\
\hline $\begin{array}{c}\text { Transferência } \\
\text { Tradução } \\
\text { literal }\end{array}$ & $18 \%$ & $40 \%$ \\
\hline $\begin{array}{c}\text { Explanação } \\
\text { Substituição } \\
\text { cultural }\end{array}$ & $6 \%$ & $6 \%$ \\
\hline & $6 \%$ & $18 \%$ \\
\hline Neutralização & $34 \%$ & $12 \%$ \\
\hline Omissão & $6 \%$ \\
\hline
\end{tabular}

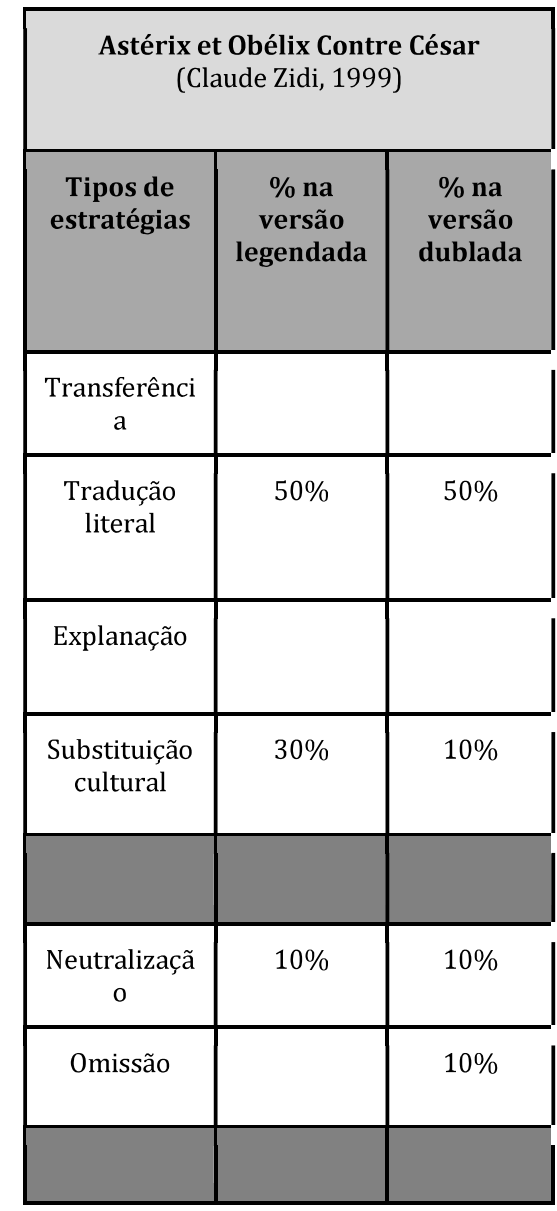

\begin{tabular}{|c|c|c|}
\hline \multicolumn{3}{|c|}{$\begin{array}{c}\text { Le Pacte des Loups } \\
\text { (Christophe Gans, 2001) }\end{array}$} \\
\hline $\begin{array}{c}\text { Tipos de } \\
\text { estratégias }\end{array}$ & $\begin{array}{c}\text { \% na } \\
\text { versão } \\
\text { legendada }\end{array}$ & $\begin{array}{c}\text { \% na } \\
\text { versão } \\
\text { dublada }\end{array}$ \\
\hline $\begin{array}{c}\text { Transferênci } \\
\text { a }\end{array}$ & $20 \%$ & $20 \%$ \\
\hline $\begin{array}{c}\text { Tradução } \\
\text { literal }\end{array}$ & $40 \%$ & $50 \%$ \\
\hline $\begin{array}{c}\text { Explanação } \\
\text { Substituição } \\
\text { cultural }\end{array}$ & $20 \%$ \\
\hline $\begin{array}{c}\text { Neutralizaçã } \\
\text { o }\end{array}$ & $10 \%$ & $10 \%$ \\
\hline \begin{tabular}{c} 
Omissão \\
\hline
\end{tabular} & \\
\hline
\end{tabular}




\begin{tabular}{|c|c|c|c|c|c|c|c|c|}
\hline $\begin{array}{c}\text { Outras } \\
\text { (variações) }\end{array}$ & $18 \%$ & $18 \%$ & $\begin{array}{c}\text { Outras } \\
\text { (variações) }\end{array}$ & $60 \%$ & $70 \%$ & $\begin{array}{c}\text { Outras } \\
\text { (variações) }\end{array}$ & $10 \%$ & \\
\hline Total & $100 \%$ & $100 \%$ & Total & $100 \%$ & $100 \%$ & Total & $100 \%$ & $100 \%$ \\
\hline
\end{tabular}

De modo geral, um número relativamente amplo de traduções literais e transferências foi identificado nos três filmes. No entanto, nomes próprios de lugares ou pessoas corresponderam a mais da metade das ocorrências ${ }^{25}$. Isso acontece porque nomes próprios são monorreferenciais por natureza. Em geral, só podem ser emprestados da língua de partida, ou seja, transferidos para a língua de chegada em sua forma original ou com alterações ortográficas insignificantes. A principal conclusão deste estudo, entretanto, é que todo o repertório de estratégias de tradução foi usado nos três filmes, tornando impossível demonstrar qualquer forma de regularidade no que concerne às normas de estrangeirização ou domesticação. Os resultados parecem ser contrários ao que Venuti e outros pesquisadores afirmaram acontecer no contexto da tradução literária.

Consequentemente, como pesquisas no campo da tradução audiovisual já demonstraram, é particularmente difícil medir o impacto que as estratégias de tradução empregadas em legendagem e dublagem podem exercer na representação da cultura de partida.

\section{Necessidade de uma abordagem mais pragmática}

\subsection{Problemas com taxonomias}

Neste estudo empírico, o modelo estrangeirização/domesticação não parece refletir de forma convincente a realidade pragmática da tradução audiovisual. Os resultados apresentados acima questionam seriamente a adequação de modelos rígidos empregados na tradução de material culturalmente específico, bem como em suposições implícitas acerca dos objetivos pessoais de tradutores/as ou distribuidores (vide seção 2.3). Na realidade, parece que os/as tradutores/as audiovisuais selecionam estratégias de tradução de acordo com a necessidade ou

${ }^{25}$ Somente nomes próprios que se referem à realidade específica da cultura de partida, por exemplo: nomes de lugares ou de pessoas famosas foram levadas em conta neste estudo. 
com uma finalidade específica ao longo do processo. 0 problema em torno das classificações descritas anteriormente surge, na verdade, de uma necessidade de classificar as estratégias. Taxonomias, por natureza, descontextualizam. Particularmente neste caso, elas apresentam referências culturais e suas traduções são relativamente independentes do contexto e de sua função no texto. Kwiecinski (2001: 10), enquanto oferece sua própria classificação de estratégias de tradução, destaca, de fato, suas limitações: “a estrangeirização/domesticação de uma transeme (unidade textual compreensível) é altamente sensível ao cotexto e ao contexto. Assim, não pode ser captada adequadamente, apenas por intermédio de uma taxonomia formal de estratégias".

Minha opinião é que fatores contextuais desempenham um papel mais importante do que normalmente se julga, especialmente em tradução audiovisual, uma vez que a mídia audiovisual é caracterizada por restrições técnicas específicas, implicando a necessidade de uma análise visual e contextual mais detalhada. Ivir (1987: 37) está entre os poucos autores que observam que:

ao selecionar as estratégias de tradução, o tradutor não toma uma única decisão acerca do tratamento que pretende dar aos elementos específicos da cultura de partida, ao invés disso, mesmo que tenha estabelecido uma ordem geral de preferências, frequentemente toma uma nova decisão para cada um dos elementos culturais relacionados a sua função específica no ato da comunicação.

\subsection{Importância do contexto}

Faz-se necessário, portanto, adotar uma abordagem mais pragmática para pesquisas em Tradução Audiovisual, enfatizando a importância do contexto na seleção de estratégias de tradução. Assim sendo, o contexto em tradução audiovisual deve ser amplamente compreendido e incluir:

- Cotexto linguístico;

- Contexto multissemiótico (imagens, sons, sinais não verbais, filmagens etc.);

- Função e relevância de referências culturais no amplo contexto da dimensão ficcional da narrativa fílmica (diegese), levando em conta as noções de Ivir (1987: 42) de cultura em foco versus cultura como background; 
- Restrições técnicas de determinada cena. Por exemplo, quando a câmera focaliza um objeto, dificultando a dublagem, assim como no caso de diálogos longos e rápidos que dificultam a legendagem;

- Gênero do filme;

- Público-alvo de um filme em particular;

- Contexto de distribuição. Por exemplo, paratextos que acompanham o lançamento do filme, os quais podem influenciar o ambiente cultural no qual o filme é recebido;

- Contexto cultural geral. Por exemplo, em que medida as referências culturais são compartilhadas entre a cultura de partida e a cultura de chegada? Qual a relação entre a cultura de partida e a de chegada?

Como Niemeier (1991: 151) salienta, "para alcançar uma tradução transcultural de sucesso o tradutor deve considerar o contexto do filme em todas as situações". De fato, determinar com precisão o contexto que envolve a tradução audiovisual e como isso pode afetar as escolhas de estratégias de tradução, ainda requer uma investigação acadêmica mais aprofundada.

\subsection{Constatações a partir de entrevistas com legendadores}

O desafio teórico a partir de uma análise empírica, aqui proposto, também parece ser confirmado por entrevistas realizadas com legendadores em fevereiro de 2004 no Special Broadcasting Service, um canal multicultural australiano que transmite filmes e programas em aproximadamente sessenta línguas diferentes e possui a própria unidade de legendagem. Durante a entrevista, os legendadores afirmaram selecionar estratégias de tradução sistematicamente, caso a caso, e não possuir qualquer propósito ideológico, estético ou didático. Quando questionados se seguem diretrizes específicas para a tradução de referências culturais, um dos legendadores respondeu: "Não. Não seguimos diretrizes em particular, apenas tomamos decisões caso a caso". Outro legendador enfatizou: Ça dépend vraiment du film et de la scène. Il faut établir des priorités' [depende realmente do filme e da cena. É necessário estabelecer prioridades]. Isso parece sugerir que, para os casos de tradução de referências culturais, o tradutor audiovisual procura selecionar a 
estratégia mais adequada para cada problema de tradução e não pré-estabelece uma estratégia geral. Tendo em vista o imediatismo de filmes e as restrições técnicas características da tradução de linguagem audiovisual, é possível constatar que o tratamento dado à tradução de referências culturais pelos legendadores prioriza o aspecto comunicativo da tradução em relação ao aspecto cultural. Desta forma, é possível argumentar que os tradutores têm como objetivo uma tradução acessível para o público-alvo, omitindo ou neutralizando, se necessário, referências culturais que de outro modo seriam de difícil compreensão para o público.

\section{Considerações Finais}

Como apresentado neste artigo, minhas hipóteses iniciais foram baseadas no amplamente usado modelo estrangeirização/domesticação proposto por Venuti e reapropriado por outros pesquisadores de tradução de referências culturais. Após empreender um estudo empírico piloto para testar essas suposições, foi possível perceber que esse modelo e, sobretudo, as taxonomias de estratégias de tradução nele fundamentadas, não foram capazes de embasar adequadamente a complexidade pragmática da transferência cultural de filmes, conforme demonstrado pelos legendadores entrevistados. Em última análise, o próprio conceito de normas precisa ser questionado.

Todavia, esses resultados se aplicam apenas à tradução audiovisual, em decorrência de restrições técnicas e de vários fatores contextuais envolvidos na escolha de estratégias, os quais se sobrepõem a possíveis propósitos ideológicos ou didáticos. Apesar dessas questões demandarem um estudo mais aprofundado do corpus, meu objetivo aqui é iniciar um debate e sugerir uma abordagem de pesquisa diferente - mais pragmática — desses aspectos em Estudos da Tradução.

Isso não significa, claro, que as noções de estrangeirização/exotização e domesticação/assimilação devam ser totalmente rejeitadas, ou que a tradução não seja uma prática discursiva. Essas ideias estimuladoras oferecem uma contribuição valiosa para as pesquisas em tradução de referências culturais, por chamarem a atenção para as responsabilidades ética do tradutor, assim como para as consequências das decisões tomadas no processo tradutório. Entretanto, ao invés de apresentar o Eu e o Outro, Familiar ou Estrangeiro, como noções fixas, é mais 
proveitoso concebê-las como mutuamente determinantes uma vez que, segundo os existencialistas, o Outro é sempre mais ou menos construído a partir do Eu e definido em relação ao Eu. Como Cryle (2000: 40) coloca: “L'autre, loin d'être un simple référent, est toujours l'autre de quelqu'un" [0 outro, longe de ser um mero referente, é sempre o outro de alguém]. Nessa perspectiva, estrangeirização e domesticação ocorrem, na realidade, ao mesmo tempo, e aquelas identidades fixas aparentes são, consequentemente, identidades negociadas, como adequadamente é demonstrado na descrição de Pym (1997: 14) acerca do tradutor como mediador intercultural: "l'espace du traduire - le travail du traducteur - se situe dans les intersections qui se tissent entre les cultures et non dans le sein d'une culture unique" [O espaço da tradução - o trabalho do tradutor - está localizado em intersecções estabelecidas entre culturas, não dentro de uma única cultura]. Ao invés de tentar aproximar o público-alvo da cultura de partida (estratégias de estrangeirização) ou de aproximar a cultura de partida do público-alvo (estratégias de domesticação), o tradutor pode permanecer na fronteira, em uma posição intermediária.

Os próprios telespectadores estão em posição intercultural. Como observado por Turner em Film as Social Practice (1993: 79) “Existe um alto grau de codificação transcultural em que o público, com a finalidade de apreciar o filme, concorda em aceitar um sistema de significados importados". Assim, não apenas tradutores e distribuidores são, portanto, responsáveis pela transferência cultural de um filme, mas o público-alvo também desempenha um papel importante. De fato, a habilidade intercultural do público, bem como sua prontidão em aceitar o Estrangeiro, são frequentemente subestimadas. Além disso, o fato de permanecer em uma sala escura de cinema para assistir a um filme estrangeiro é compreendido como um testemunho da disposição do público de aceitar essa negociação.

\section{Reconhecimentos}

0 trabalho de pesquisa que respalda esse artigo foi desenvolvido quando a autora realizava sua pesquisa de Pós-graduação como bolsista do programa International Postgraduate Research Scholarship (IPRS) da Universidade de Queensland, Austrália. A autora agradece também a seus orientadores, Jorge Díaz- 
Cintas e Pilar Orero pelos comentários, assim como a Palma Zlateva, por gentilmente fornecer dois de seus manuscritos não publicados.

\section{Referências}

Arson, P. 1988. The Aim and Function of the Subtitle - What It Does and Does Not Do. MA thesis. Université de Rouen.

Baker, M. and B. Hochel. 1998. "Dubbing", in Baker, M. (ed.) Encyclopedia of Translation Studies. London and New York: Routledge, 74-76.

Berman, A. 1985/2000. "La traduction comme épreuve de l'étranger / Translation and the trials of the foreign" (L. Venuti, trans.), in Venuti, L. (ed.) The Translation Studies Reader. London and New York: Routledge, 284-297.

Brisset, A. 2003. "Alterity in translation: An overview of theories and practices", in Petrilli, S. (ed.) Translation, Translation. Amsterdam and New York: Rodopi, 101131.

Catford, J. C. 1965. A Linguistic Theory of Translation. London: Oxford University Press.

Cornu, J. F. 1983. Traduction et cinéma. Remarques sur la traduction d'un dialogue de film. MA thesis. Université de Nantes.

Cryle, P. 2000. "Le Détour par l'autre: Sur des représentations de 'Français' dans quelques publicités australiennes". Mots: Les langages du politique 64: 39-54.

Delabastita, D. 1989. "Translation and mass-communication: Film and T.V. translation as evidence of cultural dynamics". Babel 35(4):193-218.

Faiq, S. (ed.). 2004. Cultural Encounters in Translation from Arabic. Clevedon: Multilingual Matters.

Florin, S. 1993. "Realia in translation", in Zlateva, P. (ed.) Translation as Social Action: Russian and Bulgarian Perspectives. London and New York: Routledge, 122128.

Franco Aixelá, J. 1996. "Culture-specific items in translation", in Álvarez, R. and C. Á. Vidal (eds.) Translation, Power, Subversion. Clevedon: Multilingual Matters, 52-78.

Gambier, Y. (ed.) 1996. Les transferts linguistiques dans les médias audiovisuels. Paris: Presses Universitaires du Septentrion.

Herrero, L. 2000. "Sobre la traducibilidad de los marcadores culturales", in Chesterman, A., N. Gallardo San Salvador and Y. Gambier (eds.) Translation in Context. Amsterdam and Philadelphia: John Benjamins, 307-316. 
Ivir, V. 1987. "Procedures and strategies for the translation of culture". Indian Journal of Applied Linguistics 13(2): 35-46.

Jacquemond, R. 1992. "Translation and cultural hegemony: The case of FrenchArabic translation", in Venuti, L. (ed.) Rethinking Translation: Discourse, Subjectivity, Ideology. London and New York: Routledge, 139-158.

Kwiecinski, P. 2001. Disturbing Strangeness: Foreignisation and Domestication in Translation Procedures in the Context of Cultural Asymmetry. Torun: Wydawnictwo.

Lindfors, A.-M. 2001. Respect or Ridicule: Translation Strategies and the Images of a Foreign Culture. www.eng.helsinki.fi/hes/Translation/respect_or_ridicule.htm

Mailhac, J.-P. 1996. "The formulation of translation strategies for cultural references", in Hoffmann, C. (ed.) Language, Culture and Communication in Contemporary Europe. Clevedon: Multilingual Matters, 132-151.

Nedergaard-Larsen, B. 1993. "Culture-bound problems in subtitling". Perspectives: Studies in Translatology 1(2): 207-41.

Newmark, P. 1995. A Textbook of Translation (2nd ed.). London: Prentice Hall.

Newmark, P. 2000. "The vocabulary of translation", in Schmitt, P. (ed.) Paradigmenwechsel in der Translation. Tübingen: Stauffenburg, 165-176.

Niemeier, S. 1991. "Intercultural dimensions of pragmatics in film synchronisation", in Blommuert, J. and J. Verschueren (eds.) The Pragmatics of International and Intercultural Communication. Amsterdam and Philadelphia: John Benjamins, 145162.

Olk, H. M. 2001. The Translation of Cultural References: An Empirical Investigation into the Translation of Culture-Specific Lexis by Degree-Level Language Students. PhD thesis. Canterbury: University of Kent.

Pym, A. 1996. "Venuti's visibility". Target 8(1): 165-77.

Pym, A. 1997. Pour une éthique du traducteur. Arras and Ottawa: Artois Presses de l'Université and Presses de l'Université d'Ottawa.

Robinson, D. 1998. Translation and Empire: Postcolonial Theories Explained. Manchester: St Jerome.

Schäffner, C. and H. Kelly-Holmes (eds.). 1995. Cultural Functions of Translation. Clevedon: Multilingual Matters.

Schleiermacher, F. 1813/1992. "Über die verschiedenen Methoden des Übersetzens/On the different methods of translating" (D. Robinson, trans.), in 
Robinson, D. (ed.) Western Translation Theory from Herodotus to Nietzsche. Manchester: St Jerome, 225-238.

Snell-Hornby, M. 1996. "Lingua franca and cultural identity: Translation in the Global Village", in Klaudy, K. and J. Kohn (eds.) Transferre Necesse Est. Proceedings of the 2nd International Conference in Current Trends in Studies of Translation and Interpreting. Budapest: Scholastica, 27-37.

Tomaszkiewicz, T. 2001. "Transfert des références culturelles dans les sous-titres filmiques", in Gambier, Y. and H. Gottlieb (eds.) (Multi)Media Translation: Concepts, Practices, and Research. Amsterdam and Philadelphia: John Benjamins, 237-247.

Turner, G. 1993. Film as Social Practice (2nd ed.). London and New York: Routledge.

Venuti, L. (ed.). 1992. Rethinking Translation: Discourse, Subjectivity, Ideology. London and New York: Routledge.

Venuti, L. 1995a. "Translation and the formation of cultural identities", in Schäffner, C. and H. Kelly-Holmes (eds.) Cultural Functions of Translation. Clevedon: Multilingual Matters, 9-25.

Venuti, L. 1995b. The Translator's Invisibility: A History of Translation. London and New York: Routledge.

Venuti, L. 1998a. The Scandals of Translation: Towards an Ethics of Difference. London and New York: Routledge.

Venuti, L. 1998b. "Strategies of translation", in Baker, M. (ed.) Encyclopedia of Translation Studies. London and New York: Routledge, 240-244.

Witte, H. 1994. "Translation as a means for a better understanding between cultures?", in Dollerup, C. and A. Lindegaard (eds.) Teaching Translation and Interpreting 2: Insights, Aims and Visions. Amsterdam and Philadelphia: John Benjamins, 69-75.

Zlateva, P. 2004. "Writing about 'otherness': Authoring, translating, understanding". Paper presented at the IVth International Congress on Cultural Transfer 4: Literature, Cinema, Translation. Unpublished manuscript. Vitoria: University of the Basque Country.

\section{Filmografia}

Astérix et Obélix contre César. 1999. C. Zidi. France.

Le dîner de cons. 1998. F. Veber. France

Le pacte des loups. 2001. C. Gans. France. 


\section{Biografia da autora}

Nathalie Ramière estudou Literatura Inglesa e Civilização na Universidade de Bourgogne, França. Em seguida, mudou-se para o Canadá onde lecionou francês e realizou o mestrado em tradução (2002) na Universidade de Alberta. Nathalie está desenvolvendo sua pesquisa de doutorado na Universidade de Queensland, Austrália, sob a orientação de Joe Hardwick, Anne Freadman e Barbara Hanna, como bolsista do Programa Internacional de Bolsas de Pós-Graduação. Sua tese é baseada na questão de transferência cultural em dublagem e legendagem. A autora é membro da European Association for Studies in Screen Translation e publicou diversos artigos sobre tradução e tradução audiovisual ${ }^{26}$.

\section{Biografia dos tradutores}

Morgana Aparecida de Matos é doutoranda em Estudos da Tradução pela Universidade Federal de Santa Catarina, sendo Bolsista CAPES-Excelência desde 2017/02. Mestre em Relações Internacionais para o Mercosul pela Universidade do Sul de Santa Catarina (2004). Especialista em Educação na Cultura Digital pela Universidade Federal de Santa Catarina (2016). Licenciada em Letras - Inglês pela Faculdade de Ciências e Pedagogia de Lages - Universidade do Planalto Catarinense (1995), Bacharel em Relações Internacionais pela Universidade do Sul de Santa Catarina (2002). Pesquisadora de tradução audiovisual. Tradutora de artigos científicos e de audiovisual.

Willian Henrique Cândido Moura é mestrando em Estudos da Tradução pela Universidade Federal de Santa Catarina (PGET/UFSC), na linha de pesquisa Estudos Linguísticos da Tradução e da Interpretação, desenvolvendo pesquisas em Tradução Audiovisual e Expressões Idiomáticas no par linguístico português-espanhol. Cursa especialização em Tradução Audiovisual de Espanhol pela Universidade Estácio de Sá. Graduado em Letras: Português e Espanhol pela Universidade Federal da Fronteira Sul (2017). É bolsista CNPq.

Antonia Elizangela de Morais Gehin é mestra em Estudos da Tradução pela Universidade Federal de Santa Catarina - UFSC. Bacharela em Comunicação Social Publicidade e Propaganda pelo Instituto Paulista de Ensino e Pesquisa - IPEP. Membro do Núcleo de Estudos Irlandeses (NEI) da UFSC. Tem experiência na área de Comunicação Social com ênfase em Mídia Digital.

Recebido em: 28/03/2019

Aceito em: 06/05/2019

Publicado em junho de 2019

${ }^{26}$ (n. t.) Quando da publicação deste artigo, em 2006, a autora do texto era doutoranda na Universidade de Queensland. 